\title{
NOTAS ORQUIDOLÓGICAS VII. DOS NUEVAS ESPECIES DE LA SUBTRIBU SPIRANTHINAE, BRACHYSTELE HOEHNEI Y SARCOGLOTTIS HASSLERI PARA LA A.RGENTINA
}

por MAEVIA N. CORREA ${ }^{1}$

\section{Summary}

Two new species of the subfamily Spiranthoideae, subtribu Spiranthinae, are recorded to Argentina, Brachystele hoehnei Pabst and Sarcoglottis hassleri (Cogn.) Schltr. Its description and illustration are given.

$\mathrm{Al}$ procesar el material de un reciente viaje en la provincia de Corrientes, entre las orquídeas se encontraron dos especies que resultaron ser novedades para nuestra flora. Ambas pertenecen a la subfamilia Spiranthoideae, subtribu Spiranthinae, orquídeas en su mayoría terrestres, bien representadas en nuestro país. Paso a describirlas.

\section{Brachystele hoehnei Pabst}

Fig. 1

Pabst, Bradea 1(8): 53, fig. B, 1971.

Hierba de 40-60 cm alt. sin hojas en el momento de la antesis. Raíces cortas, carnosas, fasciculadas. Tallos glabros cubiertos de vainas imbricadas, decrecientes en tamaño hacia el ápice. Inflorescencia densa de $\pm 10 \mathrm{~cm}$ long., raquis pubescente, pelos blandos, crespos. Brácteas de 8-15 mm long., estrechamente lanceoladas, agudas hasta acuminadas, subpatentes, sobrepasand o la altura de la flor. Flores de 10-12 mm, exteriormente pubescentes, sésiles a subsésiles. Sépalos blanco-cremosos con nervio central verde, el dorsal de $2,5 \mathrm{~mm}$ long. x 2,5 mm lat., anchamente ovado, casi orbicular, sépalos laterales de $4 \mathrm{~mm}$ long. x 3

${ }^{1}$ Instituto de Recursos Biológicos, INTA, (1712) Castelar, Prov. Buenos Aires, Argentina. $\mathrm{mm}$ lat. en la base, triangulares, agudos, 3nervios, anaranjados. Pétalos de $5 \mathrm{~mm}$ long. $x 8$ $\mathrm{mm}$ lat., subespatulados, obtusos, 1-nervios, pubescentes en ambos márgenes. Labelo de \pm 4 $\mathrm{mm}$ long. $\times 7 \mathrm{~mm}$ lat., trilobado, lóbulos laterales anchos, redondeados, el central estrecho, redondeado, oscuramente trilobado, cara adaxial con nervios y pelos bastante largos dispuestos en una banda a lo ancho y en el centro del labelo, cara abaxial con ancha banda papilosa, densa; en la base 2 apéndices laterales, carnosos, oscuros. Columna de $\pm 1 \mathrm{~mm}$ long. pubescente en la cara ventral; 2 estigmas tocándose en el centro.

Esta especie crece en campos anegados, a orillas de un arroyo.

Exsiccatum: Corrientes. Depto. San Roque, Ea. Caá Guazú, 11 km NE de Chavarría camino a Tacuaritas, arroyo aprox. $2 \mathrm{~km}$ al $\mathrm{SO}$ del casco, 24X-1996, Arbo et al. 6832 (CTES).

Obs. Con esta especie se eleva a 7 el número de entidades pertenecientes al género Brachystele que viven en nuestro país. Todas están presentes en el sur de Brasil, Uruguay, Paraguay y en la Argentina, en las provincias de Misiones y Corrientes, con excepción de $B$. unilateralis (Poir.) Schltr., la más austral de las Spiranthinae, que aparece en la provincia de Chubut, proveniente de Chile. 

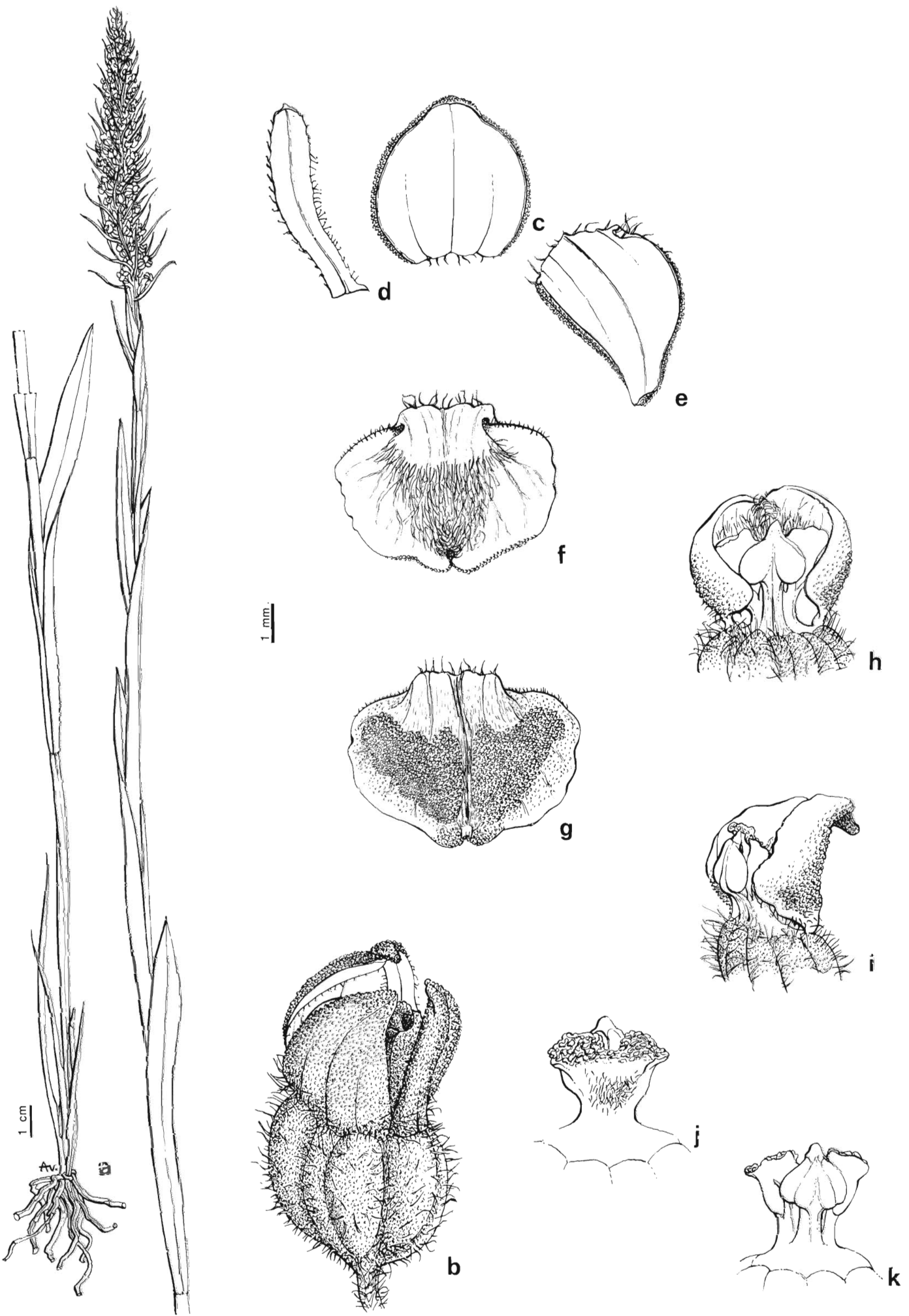

Fig. 1. Brachystele hoehnei: a, planta; b, flor; c, sépalo dorsal; d, pétalo; e, sépalo lateral; $\mathrm{f}$ labelo; g, labelo (cara abaxial); $\mathrm{h}$, labelo y columna (vista frontal y dorsal respectivamente); $i$, labelo y columna (perfil); $j$, columna (vista ventral); $k$, columna (vista dorsal). (Arbo 6832). 

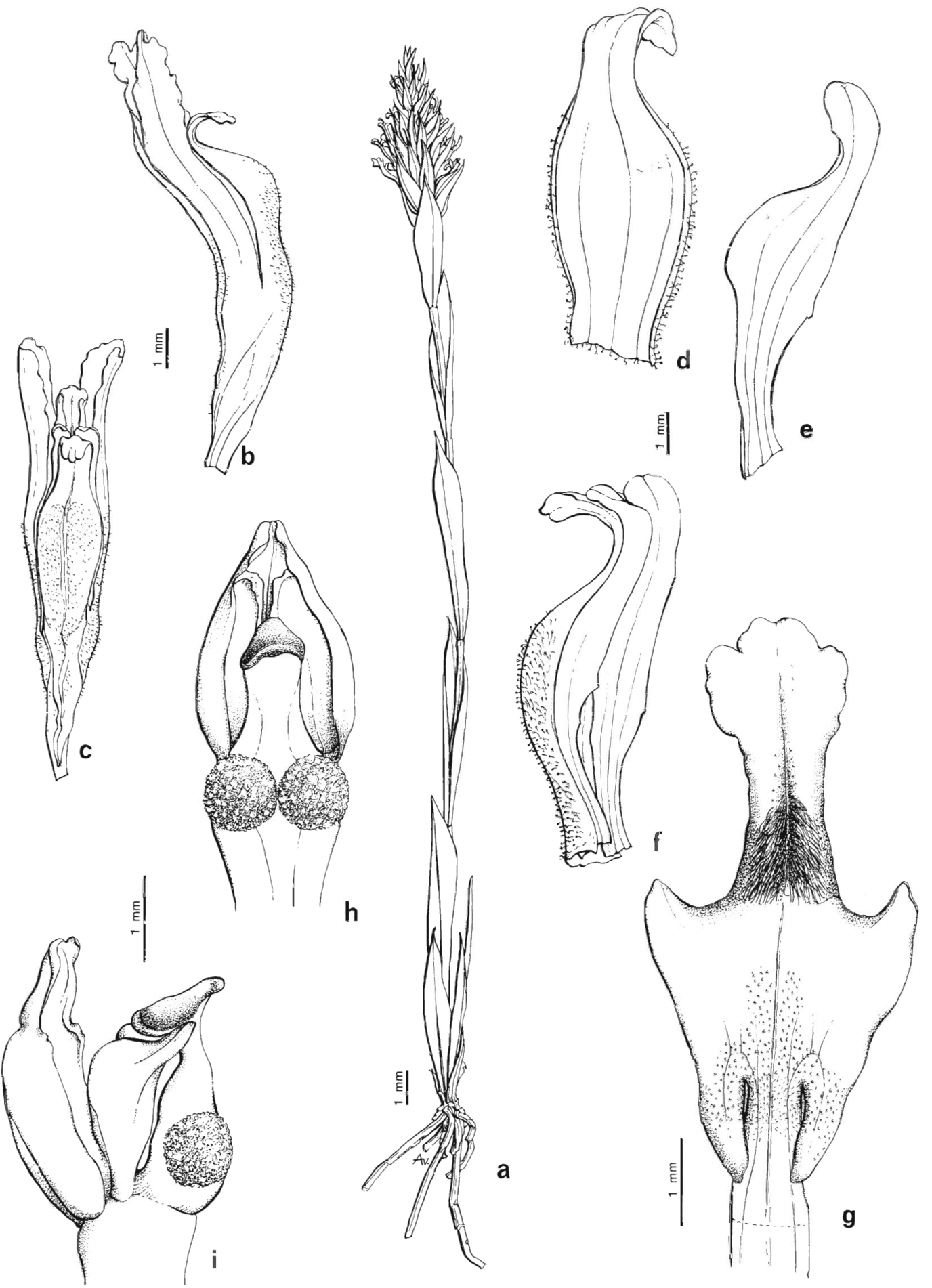

Fig. 2. Sarcoglottis hasslerı. a, planta; b, flor (perfil); c, flor (vista frontal); d, sépalo dorsal; e, pétajo; f, sépalo dorsal y pétalo en posición natural; g. labelo; h, columna (vista ventral); i, columna (perfil). (Arbo 6846). 
Sarcoglottis hassleri (Cogn.) Schltr.

Fig. 2

Schlechter, Beih. Bot. Centralbl. 37 (2): 416.1920. Spiranthes hassleri Cogn. Bull. Soc. Roy. Bot. Belgique 43: 296. 1907. Schlechter, Repert. Spec. Nov. Regni Veg. 5: 316. 1908.

Herbácea de 25-40 (-50) cm alt., sin hojas en el momento de la antesis. Raíces delgadas, carnosas, fasciculadas. Escapo glabro cubierto de vainas de 5-6 cm long., glabras, agudas. Inflorescencia de $5 \mathrm{~cm}$ long., piramidal, raquis con pelitos glandulosos, cortos. Brácteas anchamente ovadas, agudas, cubriendo el ovario y con pelitos glandulosos en el margen. Flores de $\pm 15 \mathrm{~mm}$ long., sésiles, exteriormente pubescentes, pubescencia glandulosa. Sépalos desiguales, el medio de $9 \mathrm{~mm}$ long. x 2,2 mm lat. en el ápice y $4 \mathrm{~mm}$ lat. en el centro, estrecho en la mitad superior, ápice reflexo, luego ampliamente cóncavo, los laterales de $13 \mathrm{~mm}$ long. x 2-4 mm lat., más ancho y cóncavo en la mitad inferior. Pétalos de $8 \mathrm{~mm}$ long. $x 0,8 \mathrm{~mm}$ lat. en el ápice y $2 \mathrm{~mm}$ lat. en el centro. Labelo de 10 $\mathrm{mm}$ long. muy carnoso, epiquilo redondeado con 2-4 pequeños lóbulos, mesoquilo alargado, estrecho, rollizo, pubescente especialmente hacia la base, hipoquilo obovado, cóncavo, 5-7nervio con pubescencia corta, densa y 2 lóbulos triangulares, subagudos, luego estrechándose y terminando con 2 prolongaciones carnosas, laterales. Columna de $5 \mathrm{~mm}$ long., viscidio redondeado, oscuro, antera triangular.

Especie cuyo tipo proviene del Paraguay, apareció hace algunos años en el sur de Brasil y ahora en la Argentina, donde el número de especies de Sarcoglottis se eleva a nueve. Es aparentemente escasa, habitante de campos anegados, orillas de arroyos.

Exsiccatum: Corrientes. Depto. San Roque, Ea. Caá Guazú, $11 \mathrm{~km}$ NE de Chavarría, camino a Tacuaritas, potrero Plantel, aprox. $3 \mathrm{~km}$ oeste del casco, 25-X-1996, Arbo et al. 6846 (CTES).

Obs. Especie muy afín a $S$. neuroptera (Rchb.f. \& Warm.) Schltr. Se asemeja en la forma de las piezas florales, el labelo es igualmente carnoso y rollizo pero carece de los lóbulos laterales del mesoquilo característicos de esta especie. Además las flores son más pequeñas y la inflorescencia más densa. 